\title{
Apreciación de la fruta en obras literarias (III): la fruta del Campo Lindo*
}

\author{
Amalia Castro** \\ Alejandra León*** \\ Sebastián Schoennenbeck ${ }^{* * * *}$ \\ Felipe Cussen*****
}

\begin{abstract}
Resumen
En el presente artículo abordaremos la temática de la fruta en la literatura chilena, tanto desde la tradición campesina, representada por la colección FUCOA y otros textos recopilatorios, como aquellos rescatados en las letras populares chilenas, en el ámbito de la literatura criollista y la poesía del siglo XX. Postulamos la presencia de la fruta en estos relatos y poemas como añoranza de un pasado precioso que se perdió. El deseo permanente de volver al "campo lindo" o al espacio del solaz frutal es plasmado por los diferentes autores en sus escritos.
\end{abstract}

Palabras clave: frutas, literatura, campo lindo.

\section{Appreciation of fruit in literary works (III): fruit of the Beautiful Country}

\begin{abstract}
This article will address the theme of fruit in Chilean literature, from peasant tradition, represented by the collection FUCOA and other texts collections, such as those rescued by Chilean folk lyrics and in the field of literature criollista and twentieth-century poetry. We postulate the presence of fruit in these stories and poems as precious memories of a past that was lost. The permanent desire to return to "Beautiful country" or fruity solace space is shaped by different authors in their writings.
\end{abstract}

Key words: fruits, literature, beautiful country.

Recibido: 25-10-2013 Aceptado: 30-11-2013

* Este artículo forma parte del Proyecto Fondecyt $\mathrm{N}^{\circ} 1130096$. Denominaciones de origen e identidad de vinos y agroalimentos en Chile (1870-1950).

** Chilena, Doctor(c) en Historia, Universidad Católica Silva Henríquez, Santiago, Chile, acastros@ ucsh.cl

*** Chilena, Licenciada en Literatura, Universidad Diego Portales, Santiago, Chile, alejjandra.leon@ gmail.com

**** Chileno, Doctor en Literatura, Pontificia Universidad Católica de Chile, Santiago, Chile, sschoenn@ uc.cl

***** Chileno, Doctor en Humanidades, Universitat Pompeu Fabra, Investigador Instituto de Estudios Avanzados Universidad de Santiago de Chile, felipecussen@gmail.com 
Por el campo lindo y bello

Brindaré yo con afán

(Carpeta 46, cuento 1792, “Campo Lindo”, colección FUCOA)

\section{Nostalgia por el "campo lindo": la fruta en la literatura popular y el criollismo}

En Chile, encontramos la presencia de la fruta en la literatura en diferentes tipos de producciones literarias. Una de ellas son los relatos populares campesinos recogidos en la colección FUCOA del Archivo de Literatura Oral y Tradiciones Populares (ALOTP) de la Biblioteca Nacional. La colección recopila relatos campesinos de distintas zonas de Chile y se compone de 10.695 cuentos, de los cuales 714 están relacionados con la fruta y frutales. Por otra parte, analizaremos el papel de la fruta en volúmenes recopilatorios de letras y poesías populares chilenas, con una presencia importante en Canciones populares chilenas (Acevedo Hernández, 1939), Chilena o cueca tradicional (Claro Valdés, 1994), Aunque no soy literata (Navarrete, 1998), Los diablos son los mortales (Navarrete y Palma, 2008) y El folklore de Chile (Pavez, 1970). Asimismo, escogimos como contrapunto una obra narrativa representativa del criollismo, Días de Campo (Gana, 1916), en el que la fruta aparece en una importante cantidad de relatos. En todos estos ejemplos, la importancia de las menciones a la fruta estriba en que constituye el punto de partida para describir situaciones de vida y paisaje, con el intento de reconstruir un mundo que, al parecer, ya no existe.

En efecto, en dichos relatos la fruta toma diversos papeles, ${ }^{2}$ mayoritariamente en términos de reconstrucción de memoria. La intención es rescatar del olvido las costumbres antiguas, a través de la recreación de un campo que, aunque en el relato campesino muchas veces pueda ser duro (por las condiciones de vida, el trabajo, la pobreza,

1 La colección FUCOA (Fundación de Comunicaciones, Capacitación y Cultura del Agro) depende del Ministerio de Agricultura y posee personalidad jurídica desde 1982, encargándose de generar espacios de participación en el rescate de la cultura y tradición campesina. Uno de sus objetivos es colaborar en la gestión de actividades culturales en el mundo rural, no solo para el rescate de tradiciones, sino también para sensibilizar y acercar el campo a la ciudad, como una manera de preservar el patrimonio cultural.

2 Para más detalles, véase Castro, 2011; Castro, 2012; Castro et. al., 2013. 
el hambre y el frío), finalmente siempre es endulzado por la presencia de la fruta, evocadora por excelencia de momentos gratos o comparable a cosas exquisitas.

En estos relatos es posible apreciar metáforas de abundancia relacionadas con la fruta, ya sea en torno a los alimentos, lugares o sexualidad fértil. El recuerdo, en todo caso, permanece como lo más atractivo en la mayoría de los relatos.

En el norte de Chile, especialmente, donde hoy abunda la sequía que es sinónimo de pobreza y hambre-, se evocan historias pretéritas, de los años 30 del siglo XX, donde había agua para regar los campos que proveían, entre otros productos, de jugosos melones y sandías. Tanta era la abundancia de fruta, que se regalaba a los afuerinos. ${ }^{3}$ El sur del país nos relata, para la misma época y en idéntico sentido, la importancia de la fruta producida en forma silvestre por intermedio del creador, en un campo que no deja morir de hambre a nadie. En "El huacho José", una familia campesina muy pobre, sin madre y con un hermano inválido, complementaba su alimentación con frutas silvestres "que gracias a Dios en Arauco son abundantes; el Viejito aquí no deja morir a nadie de hambre: con las primera lluvias brotan de la madre tierra changles, callampas (champiñones), cuando comienza a entibiar el sol de la primavera aparecen los dihueñes, cógüiles (fruto del copihue), nalcas, maqui, avellanas, murtilla y así para cada estación un fruto diferente y delicioso manjar para los pobres". ${ }^{4}$

Considerando el corpus literario presentado, la fruta figura básicamente de dos maneras: como parte de un paisaje o como metáfora de un cuerpo, por lo general, erotizado. La aparición de la fruta tanto en el paisaje como en el rostro o en la figura humana rompe la aparente incompatibilidad y distancia entre ambos. Las frutas forman parte de un paisaje determinado, siempre añorado. En este sentido, la fruta no puede ser separada del frutal ni de sus entornos. El campo chileno florido y fértil es re-construido y construido recíprocamente desde estos relatos, que muchas veces son generados desde las ciudades, con una mirada

3 Raúl Díaz. "Sequía". Comunidad Agrícola Uchumi Diaguitas, Vicuña, IV Región, S/F. BN, ALOTP, Colección FUCOA, Carpeta 18, cuento 701.

4 Bernardita Mancilla Sáez. "El huacho José". Comuna Cañete Bío Bío, 1995. BN, ALOTP, Colección FUCOA, Carpeta 22, cuento 835. El autor afirma tener 71 años al momento de escribir este relato, con lo que su infancia puede ubicarse en la década de 1930. 
nostálgica. Este sentimiento responde al modelo de la Arcadia perdida, figura metafórica e idílica de un reino mítico caracterizado por la armonía de las relaciones entre sus integrantes y la complementariedad de sus actividades (Melón Jiménez, 2012: 184). Así, se desencadena la formación de una imagen paradisíaca del campo: un locus amoenus, un locus de amor dulce e inocente ("Mi abuelito me contó que la vida en el campo es como mágica, alegre, tranquila"5), un generoso locus que regala alimentos y frutas sin exigirnos gran esfuerzo. Vemos aquí la socialización de un paisaje arquetípico, creados por un imaginario colectivo, que ha sido compartido y aceptado (Nogué y San Eugenio Vela, 2011: 30): “Tu parcela nos regala la visión de unos duraznos floridos, duraznos que con paciencia esperas que den frutos y esos frutos los ves crecer y madurar, los sacas con tus hermosas manos y los haces mermelada, el mejor regalo para unas niñas bulliciosas que cada año llegaban a pasar las vacaciones con la abuela". ${ }^{6}$

Este paisaje idealizado en el cual la fruta forma parte presenta, no obstante, ciertas rupturas con la tradición retórica de las figuras (Curtius, 1999: 286). Si bien puede identificarse como un locus amoenus en cuanto es una descripción de un bello y benigno espacio natural cuyos elementos esenciales son el árbol, el prado, el arroyo, la brisa y el canto de los pájaros (Curtius, 1999: 280), el paisaje frutal del corpus literario seleccionado incorpora un trabajo agrícola despojado de connotaciones negativas y modifica la estación del año. Mientras la idealización virgiliana de la Arcadia supone una eterna primavera que motiva el discurso bucólico, el paisaje frutal en Chile requiere más bien una marca estival, es decir, una prolongación de la temporada de cosechas. Al mismo tiempo, el trabajo, en tanto marca que particulariza el paisaje local chileno, aparece exento de un valor comercial para dar lugar al intercambio generoso de la fruta como fuente divina de alimentación.

Las palabras usadas para la descripción de este paisaje, en el que la fruta ocupa un lugar fundamental, no pueden ser tomadas a la ligera, ya que las mismas son centrales para diferenciar concepciones propias del mundo; por medio de esta terminología una cultura pone de manifiesto

5 Irina Sandoval Moreno. "Margaritas Secas". Chile, 1998. BN, ALOTP, Colección FUCOA, Carpeta 55, cuento 2130.

6 Irene Porra. “Las tres Marías", Valparaíso, 1993. BN, ALOTP, Colección FUCOA, Carpeta 7, cuento 245. 
lo que ve en su entorno (Berque, 2009: 58), es decir, su visión del paisaje que construye. Esto es lo que Berque denomina "pensamiento paisajero", que integra una dimensión clave para el mundo del campesinado: la experiencia del hacer, no solo la de conocer/contemplar. El pensamiento paisajero es el sentido profundo del paisaje. "Este sentido profundo es la autenticidad de un paisaje en el que la vida de un hombre está en armonía con la naturaleza" (Berque, 2009: 74). El paisaje, por ello, está en la mirada de un observador específico, empapado de su bagaje cultural y genético (Felsenhardt, 2009: 76), a lo que debe sumarse una nueva dimensión comunicativa, que dota de identidad al paisaje (Nogué y San Eugenio Vela, 2011: 27). De este modo, una mujer de 70 años recuerda así su infancia en el campo de sus abuelos:

vuelvo a sentir el aroma a flores y fruta madura, especialmente la del durazno haciéndome agua la boca, chorreando su jugo por mis brazos pequeños [...]. Y, entre cada hartazgo con ciruelas o damascos, los juegos; mis casas de muñecas entre los arbustos, o en diminutas cavernas horadadas en cualquier montón de tierra, semejando aquellas del camino que yo imaginaba habitada por gnomos y duendes. ${ }^{7}$

Así, el campo se presenta como un lugar edénico:

En primavera [los duraznales] ofrecían una visión mágica, toda envuelta en una nube de color rosa, al atardecer con los últimos rayos del sol parecía que los duraznos en flor se alzaban para pintar el cielo (...). Tengo el recuerdo de un paisaje bíblico. De abundante cosecha de variados frutos, generosos en exquisitez y aromas, por todas partes asomaban sus copas: higuerales, naranjos, nogales y limoneros. ${ }^{8}$

De este modo, se conforma una dicotomía entre el retrato de la ciudad y del campo, que pareciera responder a ideales higienistas de ciudad más que a percepciones modernas de la misma. Para el higienismo, la ciudad es una especie de monstruo, un elemento de perversión, una zona de

7 Amelia Salinas. “Fotografía en Sepia”. Santiago, 1998. BN, ALOTP, Colección FUCOA, Carpeta 50, cuento 1931.

8 Sylvia Villaflor. “La quebrada de los Pinto". La Serena, 1993. BN, ALOTP, Colección FUCOA, Carpeta 15, cuento 561. La autora, profesora rural jubilada, tenía 72 años al momento de escribir este relato, por lo que, si consideramos que este es un relato de su adultez, el mismo podría situarse en la década de 1950. 
decadencia humana (Coss Lanz, 2009: 161) y podemos ver también esta perspectiva en los relatos campesinos, para quienes la ciudad (la Gran ciudad, la que se encuentra alejada del núcleo campesino, no la ciudad más pequeña y cercana donde realizan sus intercambios comerciales) es "bulliciosa y desgastadora". ${ }^{9}$

Así, el campesino transplantado a la ciudad se pregunta: ¿Cómo será vivir sin que la tierra nos acaricie el rostro? (...) no hay zarzamoras ni sauces donde columpiarse, ni esteros ni golondrinas, ni treiles anunciando lluvias (y entonces), ¿cómo sabrá que va a llover?". ${ }^{10}$

Se refleja, en este relato, una visión del mundo armónica con el entorno que se rompe al perder el contacto directo con la tierra. Esta mirada, que concibe la existencia humana y su entorno en un contexto armónico, se replica en los versos populares analizados.

En efecto, en ellos podemos ver representada la fruta como un elemento que significa abundancia, alimento. Es algo que se comparte, ya sea por bondad o por comercio, y que responde a la necesidad elemental de alimentarnos, lo que puede apreciarse en la obra del poeta popular Daniel Meneses ${ }^{11}$ :

Por último, el vejetal

En invierno y en verano,

Es de todo ser humano

Alimento sustancial;

Con el viento mineral

Se mece el árbol frondoso;

También un fruto sabroso

Nos da después de florido;

Maduro i descolorido

Pero mui dulce i jugoso. (Navarrete y Palma, 2008: 162)

La fruta se presenta, por tanto, como regalo de vida, de la naturaleza, de un ser superior. Cumple un ciclo, además: hay fruta verde y fruta madura.

9 Sofía Paredes Fernández. “Fauto y el León” (sic). Huasco, III Región, 2004. BN, ALOTP, Colección FUCOA, Carpeta 157, 19 HA.

10 Doris Meza Azócar, "Carta Abierta”. Teno, VII Región, 1999. BN, ALOTP, Colección FUCOA, Carpeta 68, cuento 2705.

11 Sobre el poeta: "Daniel Meneses fue uno de los grandes poetas populares entre quienes llegaron a publicar sus composiciones en pliegos a finales del siglo XIX y comienzos del XX" (Navarrete y Palma, 2008: 27). 
No responde, entonces, a una imagen de muerte: todo lo contrario. Son regalos para la amada, regalos para Jesús, o desde la naturaleza misma para el hombre, quien las contempla en su belleza natural (árboles) o bien las consume. Las frutas se constituyen en un premio al trabajo del año, como regalo precioso o como objeto de celebración. La fruta, en estos casos, se ha utilizado como medio de establecimiento de relaciones interpersonales y del hombre con la divinidad. En este sentido, la dinámica del Don es bien conocida (Mauss, 1924; Sánchez Montañés, 2009; Abduca, 2007): un bien que se entrega a otro y que genera en ese otro el compromiso de realizar la misma acción con el dador. Esta relación puede establecerse entre personas o entre los seres humanos y los dioses. Por eso, en diversos lugares del mundo (el antiguo Egipto, Oriente, Roma y América precolombina), las celebraciones relacionadas con lo divino siempre involucraron elementos frutales en distintas formas, ya fuera como comida o bebida (Reixach, Cervera y Salas-Salvadó, 2005). Y es que, de acuerdo a Maximiliano Salinas, existe una profunda relación, casi telúrica, de la religión popular con los productos agrícolas; una religión popular más folclórica y rústica, ligada a los ciclos agrícolas y de la naturaleza (Salinas, 1985). Así lo retrata Daniel Meneses:

Jira el sol en su carrera

Rodeado de sus planetas,

Satélites i cometas

Que circulan en su esfera;

I cuando ya el año entera

Se viste el campo de luto

I le rinde atributos

La más hermosa colina,

I por la gracia divina

La tierra da mil productos.

(Navarrete y Palma, 2008: 181)

Puede observarse en esta poesía popular los tópicos a los que antes nos referíamos. Aquí la fruta se presenta, dentro de un ciclo virtuoso de la naturaleza, como un regalo precioso dado por la gracia divina al agricultor esforzado, que logra mantener un trabajo en su campo durante todo el año para cosechar los frutos en el verano, coincidiendo, en este hemisferio, con la época del nacimiento de Cristo y su celebración, la Navidad. 
La fruta, de este modo, tiende a alabar la creación divina, mostrando su perfección vía naturaleza. Así puede verse en el siguiente relato, en donde San Pedro dialoga con Dios:

El mundo no está bien hecho, San Pedro dijo, mire señor, ahí al otro lado esas plantas tan chicas y medios frutos que tienen y estos inmensos árboles y la fruta tan rechica que tiene; no Pedro, el mundo es así y así será siempre le dijo Dios a san Pedro, en eso estaban cuando de repente Dios con su poder hace que el peral que estaba San Pedro comiéndose su pan tranquilamente debajo de ese peral de arriba le cae una pera en plena cabeza que a San Pedro se le cae manso ni que grito ay señor! Qué te pasó Pedro, señor me cayó un fruto de este árbol en la cabeza y Dios le dijo y si te hubiera caído uno de esos que están ahí al otro lado del potrero o sea un zapallo en la cabeza, te mata, ves Pedro le dijo Dios; el mundo está muy bien hecho, le dijo Dios a San Pedro. ${ }^{12}$

El uso de la fruta como metáfora no es privativo de este tipo de experiencias religiosas. Lo encontraremos también en el tratamiento dado a la fruta en su característica más sensual, en referencia a la sexualidad y al amor. En la poesía popular, se encuentran ejemplos en donde aparece el tono picaresco característico de esta poesía, siendo la fruta un elemento fértil que se utiliza por su versatilidad y doble significado. El hecho es evidente en este fragmento de "Zamacueca":

Dicen que la palma es grande

y que es árbol coposo,

y de los frutos que da,

los mejores son los cocos.

Ofrécele a esa niña,

no seas loco;

ofrécele la palma,

menos los cocos.

Menos los cocos, sí,

y ella decía

que la palma sin cocos

no le servía. (Acevedo, 1939: 119)

12 Juan Poblete. “Así es Dios y el mundo". Cuncumén, V Región, 1995. BN, ALOTP, colección FUCOA, Carpeta 20, cuento 772 . 
Este sugerente poema, que plasma una clara imagen fálica, deja en claro que la sexualidad no es solo una realidad biológica del hombre, sino que también es construida social y culturalmente; ha superado la mera satisfacción corporal para convertirse en un eje organizativo social y reproductor de relaciones morales (Amar, 2005; Bidegain, 2005; González et. al., 2007). Así, la construcción de la sexualidad y la pesquisa por el placer nos trasladan nuevamente a ese paisaje idílico que comentábamos anteriormente, un "locus amoenus que recrea el paraíso terrenal" (Miaja, 2009: 1627) y que es reconocible en la poesía popular, por ejemplo, en la cueca "Qué bonito es Peñaflor", describiendo un paraje edénico donde la mujer - representada por flores-, junto a las frutas, ocupan un lugar central, un espacio dedicado al amor y al goce pleno: "se vive amando, sí/jardín de flores/de frutas y verduras/que son primores" (Valdés, 1994: 522).

Este tipo de imágenes descritas parecieran ser necesarias: existe una represión que desde el siglo XVIII obliga a alterar un lenguaje para "desdibujar y deconstruir todas las palabras de temática sexual, tratando de crear un lenguaje censurado, para cualquier oído que lo escuche. Se crea entonces un vocabulario autorizado y restringido, especial para el sexo" (Moncrieff, 2007: 4-5) y, en este caso, para la representación, por añadidura, de lo sensual, de todas las palabras que no pueden ser dichas para describir sentimientos amorosos. Puede observarse esta situación en el relato "La finca de don Chuma". ${ }^{13}$ Es la historia de un equívoco, pues don Chuma cree que ha sido engañado por su mujer - llamada, no por casualidad, Flor-, abandonándola, prefiriendo irse antes de confrontarla y hablar de la situación. Ella lo sigue, sufriendo una transformación en el camino, pareciendo un gañán: hace todos los trabajos masculinos y así se masculiniza su apariencia. Cuando por fin, años después, encuentra a su marido, este no la reconoce; pero finalmente el matrimonio se perdona en la edad madura y son felices. Lo interesante para nuestro análisis son las payas que intercambian entre ellos al momento de reencontrarse, pues ellas ejemplifican el lenguaje antes mencionado, utilizándose en primer término a las uvas, como metáfora del placer que da una mujer al hombre:

13 Teodosio Coquidan. "La finca de don Chuma", Parral, 1996. BN, ALOTP, colección FUCOA, Carpeta 33, cuento 1289. El autor es, por añadidura, vinicultor (así lo expresa él mismo). 
Yo fui viña con tus manos me cultivaste(s)

las uvas las cosechaste(s)

y con ellas tú gozaste.

Te fuiste y me dejastes sin saber por qué.

El marido responde reconociendo que habitó su cuerpo y gozó con él; sin embargo no pudo soportar la presencia de un usurpador, otro hombre, calificado como ladrón, ya que la mujer, como su esposa, queda definida como su pertenencia y también como su creación: la mujer es mujer después de la exploración de su sexualidad:

Si en verdad tú eras mi viña

Con mis manos te cultivé

La cosecha era muy buena

Yo a ella la saborié,

Me fui y te dejé

Porque un ladrón me encontré.

La situación se resuelve porque un tercero en discordia, llamado Manuel, aclara la situación, proclamando su propia inocencia y la de la mujer:

Yo soy Manuel el Venado nombre que siempre he tenido

Porque me andar sin rodeos le digo a On Chuma que lo que él cree

Está equivocado si desea saber la verdad aquí

Va es cierto que me metí a su viña la cuidé

Con gran amor, las uvas eran muy ricas

pero nunca las aproveché, aquí te entrego tu viña,

la dejo como la encontrado las uvas son muy

ricas, pero nunca la he aprobado.

El tema, que vincula mujer y frutas como sinónimo de placer, de la satisfacción de los sentidos, del ver, tocar y saborear, no es nuevo. El mismo podemos verlo reflejado en diversas obras de literatura, como en Libro del Buen Amor, el Decamerón (Lacoste y Castro, 2013) o los cuentos de Las Mil y una Noches (Lacoste, Castro y Yuri, 2012). Además, en representaciones pictóricas tradicionales, donde se relacionan simbólicamente a las frutas con los cuatro sentidos: olfato, gusto, oído 
y tacto, aludiendo además a vicios y virtudes: "Las flores y frutos hacen referencia a la belleza, simbolizando a mujeres y niños" (Rubio, 2011: 3). Por ello, las ideas expuestas son motivos recurrentes asociados a la figura femenina en la literatura universal (Miaja, 2009: 1627). De este modo, encontramos dichas imágenes expuestas en relatos tradicionales, donde aparecen "ojitos de uva", ${ }^{14}$ "ojos de avellana", 15 "boquita de guinda", 16 "ojos de aceitunas", ${ }^{17}$ "bocas redondas y rojas como cerezas" ${ }^{18}$ La mujer puede ser "robusta y sonrosada como los brotes del duraznero cuando termina el invierno"19 y despertar sentimientos lúbricos “...la boca se le hacía agua cada vez que la miraba, se le caían las babas pues se le antojaba como un fresco y jugoso limón".$^{20}$

Antiguamente la sexualidad, esa fundante de vida, era vista como un impulso creativo y placentero. Este hecho cambia en el Medioevo, cuando tanto la Iglesia castellana como la carolingia, en los siglos XI y XII, intentaron normar el matrimonio, estableciendo normas y ritos que terminaron por hacer del matrimonio una institución religiosa y monógama, y del instinto sexual algo demoníaco (Bidegain, 2005: 44; Vera Gamboa, 1998).

Así, la mujer y su pureza debían quedar resguardadas con criterio de clase; como fuerza reproductiva no podía ser mancillada, sino entregada a un solo hombre para hacer vida con él y para él ("Tú trabajarás para ti y ella para ti y para ella, como debe ser. El hombre no debe casarse sino cuando sea su conveniencia". Gana, 1916: 105). Perdida la pureza, se pierde el valor de la mujer; así sucede también en el campo, en historias recogidas por la literatura criollista. Veamos este ejemplo: la Maiga, hija de don Manuel, dueño de la pulpería Las tres Esquinas, ha muerto, y en su funeral, donde los campesinos se emborrachan con vino para pasar su pena, se descubren los motivos de su muerte. El padre de la joven,

14 Carolina Bravo Larenas. "Tengo frío papi". San Clemente, VII Región, 2002. BN, ALOTP, colección FUCOA, Carpeta 88, cuento 3659, 34 A).

15 Héctor Valenzuela. "Pancho Jote". Coihueco, 1999. BN, ALOTP, colección FUCOA, Carpeta 65, cuento 2608 .

16 Héctor Valenzuela. "Pancho Jote". Coihueco, 1999. BN, ALOTP, colección FUCOA, Carpeta 65, cuento 2608.

17 Eliana Silva. "Conquel y Pediu”. Santiago, 2000. BN, ALOTP, colección FUCOA, Carpeta 73, cuento 2933.

18 Eliana Silva. "Conquel y Pediu”. Santiago, 2000. BN, ALOTP, colección FUCOA, Carpeta 73, cuento 2933.

19 Helga Villagrán Gómez. “El Chindo". Las Condes, RM, 2004. BN, ALOTP, colección FUCOA, Carpeta 157, cuento 8 HA.

20 Víctor Norambuena. “Amor de pobre”. Yumbel, VIII Región, 1993. BN, ALOTP, colección FUCOA, Carpeta 10, cuento 350. 
buenamoza y cantora, niega su mano al amor de su vida y la vende, la obliga a prostituir su virginidad a un "caballero". El joven, entonces, rechaza a la Maiga por su traición. Es tanto su dolor, que, alcoholizado, termina apuñalando a una persona, lo que lo lleva a la cárcel. La Maiga "se murió de pena porque yo no me acerqué a ella... porque me quería!" (Gana, 1916: 23).

De este modo, encontramos las metáforas de la sexualidad fecunda, pujante y creadora de vida, mezcladas con la sensualidad de un encuentro íntimo, en un lenguaje oculto entre parras y vendimiadores. Parra/ uva/mujer/sexo parecieran desprenderse de los relatos campesinos, moldeados por una moralidad impuesta tiempo atrás por lo más conservador del mundo católico:

Los tomadores de uva sacudían con frecuencia sus manos sumidas en el sesante (sic) rocío que lengüetea las parras casi indiferentes, idolatrando unas piernas que se dibujan al molde de los elásticos ajados, cubiertas de un ropaje sensual y erótico hasta donde se resbalan los dedos empalados de frío, que quieren calar la médula de sus huesos arrodillados al revés de una cáscara desvalida que acaricia sus genitales maduros al calor de las verijas desaseadas, distantes a la fertilidad de la tierra que los ha gestado y que hoy ya los ve nacer. ${ }^{21}$

Los parronales "lujuriosos", 22 poseedores de una fuerza vegetal vital, exuberante, eran el escenario verde de las relaciones amorosas entre los trabajadores de la viña. José María, vendimiador temporero y muy "estimado por los patrones por pisar el orujo con ritmo y vigor, como preocuparse de la temperatura e ingredientes en la fabricación del vino" produjo una preocupante realidad: tres embarazos a trabajadoras solteras del fundo. ${ }^{23}$ Pareciera que el calor del sol se traspasaba a los cuerpos y la potencia fértil de la parra al deseo humano. Y la parra no era inmune a estos sentimientos; en el relato "A mi sombra" habla una parra enamorada de una vendimiadora, Rosita, descrita como una joven de 19 años, "morena, ojos negros y penetrante mirada (...) una figura esbelta, piernas largas y finamente torneadas, un busto joven lozano que percibo

21 Claudio Richardy. “La vendimia”. Peñalolén, Santiago, RM, 1993. BN, ALOTP, colección FUCOA, Carpeta 1, cuento 21.

22 Erasmo Bernales. “El ‘Churrito’ de Chañar Blanco”. Vallenar, 1993. BN, ALOTP, colección FUCOA, Carpeta 11, cuento 407. El autor tenía 80 años al momento de escribir este relato. 
muy cerca (...)". La parra siente el contacto de Rosita (nuevamente, una protagonista con nombre de flor) en su cuerpo como si fuera un humano: "Siento sus manos en mis ramas, sus dedos en mis hojas y su cuerpo pegado a mi tronco, es un éxtasis; algo que no puedo describir, siento esa pureza que irradia por sus poros y que llega a lo más profundo de mis raíces". Luego de una escena de sexo entre Rosita y un trabajador, a la sombra de esa misma parra, el vegetal se sumerge en un profundo dolor, y la parra herida ya no puede sentir la pureza de la, ahora, mujer que se entregó. Se reitera la no percepción de la pureza de la joven. Es tanto el dolor de la parra, que teme no poder dar fruto. Tres meses pasan, hasta que, nuevamente a sus pies, la pareja humana discute y el hombre termina muy fuertemente la relación amorosa. Rosita queda desolada y termina ahorcándose, colgada de las ramas de la parra que la adoraba y que llora por ella, tal vez por toda la eternidad. ${ }^{24}$

Los frutales juegan un papel en el juego amoroso, como la joven que le regalaba dulce de membrillo hecho por ella a su amor. ${ }^{25}$ Son, también, guardianes fieles de amores clandestinos. A la sombra de un árbol que daba frutos idénticos a la frutilla, Noelia "cada tarde, se encontraban [con Miguel] a escondidas de don Pedro, bajo la sombra de aquel árbol de frutillas quien era testigo del amor que existía entre ellos y que cada día florecía con mayor fuerza, tanto como las flores del magnolio blanco". El padre se opone a este amor juvenil, entre la hija del patrón del fundo y un trabajador pobre; tan fuerte fue la negación del padre de Noelia que los enamorados fallecen $y$, desde entonces,

cuenta la gente del sector, que en las noches de luna llena, en el jardín de aquella casa patronal, algunas personas han observado a Noelia, corriendo por entre los laberintos de legutrinas, para llegar a aquel "árbol de frutillas", vestida de novia para encontrarse con Miguel, quien se presenta como un picaflor y es en aquellas noches cuando el árbol florece y se ilumina, sin importar la estación del año que se encuentre. Majestuoso árbol que sigue siendo cómplice de su amor. ${ }^{26}$

23 Claudio Alegría. "La humildad de José María". Fundo La Palma, Curtiduría, Talca, 1993. BN, ALOTP, colección FUCOA, Carpeta 6, cuento 196.

24 Luis Apablaza. "A mi sombra". Fundo El Carmen, Putaendo, 1993. BN, ALOTP, colección FUCOA, Carpeta 18 , cuento 687.

25 Alberto Villegas. “Doña María Carlota”. Comunidad de Canto del Agua, Huasco, 1998. BN, ALOTP, colección FUCOA, Carpeta 45, cuento 1744.

26 María Carolina Castro Cerda. "La novia del jardín”, Linares, VII Región, 2003. BN, ALOTP, colección FUCOA, Carpeta 118, cuento 5131-230 HA. 
El amor frutal también se manifiesta en esta tonada recopilada por Héctor Pavez, perteneciente al folklore popular:

Las flores de las naranjas

se reparten con el viento.

Así me tiene tu amor

repartido el pensamiento (Pavez, 1970)

El motivo amoroso que hemos identificado puede estar articulado con el escenario en el cual la fruta toma lugar. En efecto, este añorado "campo lindo", al ser identificado como un locus amoenus, no puede ser dislocado con respecto a una tradición bucólica en la cual la voz poética, enmascarada de pastor, canta las penas amorosas gracias a la compañía de las bellezas naturales tales como los árboles generosos en frutas.

Este tono amoroso será mantenido por algunos autores del período que analizaremos a continuación, aunque las imágenes de la fruta y sus asociaciones tendrán cambios en algunos aspectos, en especial los relacionados con la vida y la muerte.

\section{Poesía del siglo XX}

La recopilación más importante de inicios del siglo XX es Selva Lírica (Molina y Araya, 1917), en la que la fruta ocupa un lugar importante, con preeminencia de un subproducto como el vino, y lo mismo ocurre en una antología posterior, que cubre un amplio espacio temporal, Poesía chilena contemporánea (Arteche, 1984).

Al mismo tiempo, también pueden encontrarse menciones en la obra específica de autores canónicos como Gabriela Mistral y Pablo de Rokha, especialmente en Epopeya de las comidas y bebidas en Chile (de Rokha, 1949).

En la poesía de este período, el amor también es expresado a través de frutas como la naranja, utilizada como medio para expresar sentimientos amorosos. En la pintura es símbolo de fertilidad, ya que este árbol puede tener a la vez flores y frutos. En las coronas y ramos nupciales siempre se lleva el azahar, que es una flor blanca como perla y aromática, símbolo de pureza, por lo que sirve de adorno a la novia el día de bodas (Pérez Rioja, 1969). Como todos los frutos de numerosas pepitas, la naranja es símbolo de fecundidad, representando en ciertos casos a ovarios fértiles (Molina 
Palma, 2004). Estas ideas se ven reflejadas en la poesía de Juvencio Valle "La Naranja":

La naranja despunta desde adentro: en el espacio tibio tiene un hueco: se inicia en sus entrañas, y qué rosa, qué sustancia interior, qué mal alzado si en la mano turbada centellea.

[...]

Qué apretada la veo, qué dureza de mineral ardiente le descubro; qué inflamada la encuentro; qué ceñida a su teclado de oro, qué madura para morir entre garganta y lengua. (Arteche, 1984: 70)

La imagen de "apetitosa" en el amor es latente en poesía, una imagen reforzada, en este caso, por el hecho de que la niña de sus amores tiene "labio de fruta".

Del mismo modo, la literatura de este período también rescata la asociación fruta/mujer. Así, encontramos desde alusiones abiertamente sexuales —sandía abierta "como huasa sin calzones" (De Rokha, 1949: 20) - hasta expresiones más sutiles, como los "labios cerezos" de una virgen enferma, "báquica y tísica" (González, 1917: 9), pasando por una moza ardiente de quince años, Teodorinda, "tez de durazno, boca de guinda" (Pezoa Véliz, 1917: 351). También, mirada dulce "como la uva del parrón" (Acuña Núñez, 1917: 361) al igual que "ojos rasgados" que contienen "el fuego de un vino viejo de racimos asoleados" (Pezoa Véliz, 1917: 351).

Las asociaciones descritas remiten, en su mayoría, a un paisaje campesino. El tema del árbol guardián de amores está presente en esta etapa, como el limonero que daba sombra a un par de enamorados en el campo (Pezoa Véliz, 1917: 346). El limón sigue siendo protagonista de amores campesinos en esta paya: “QQue viva misiá, Juanita/cogoyito de limón, / candadito de mi pecho, / llave de mi corazón!" (Vicuña Cifuentes, 1917: 380). Una fruta como el membrillo sirve, también, para denunciar a un personaje avaro (Vicuña Cifuentes, 1917: 380). 
Si bien en la literatura modernista y poesía contemporánea pareciera denostarse a la fruta o asociarse a lo podrido, lo inalcanzable, la muerte, más pareciera tratarse de ausencia, de un dolor por lo que ya no es o no está; una nostalgia por el pasado, por ese locus amoenus de los relatos campesinos, el mismo dolor instalado en el relato de las campesinas transplantadas a la ciudad. La diferencia es que ahora la distancia se eleva, se manifiesta más sutil, más hermosa a pesar del dolor. El sentimiento es físico sobre algo que falta, un hueco en el alma, en la vida y en el corazón, tal como atestigua el poema de Efraín Barquero "Aquí y allá", en este fragmento:

y adentro de mi cuerpo, me falta la casa

con huerto y todo, con utensilios inútiles.

Me falta el corazón con todas sus pepas

y el ombligo familiar de las frutas.

Y cuando hace buen tiempo, me faltan los floripondios

para chacotear a lengua viva con los amigos. (Arteche, 1984: 203)

Faltan el corazón con pepas y el ombligo de las frutas, ambas cuestiones que tienen que ver, tanto simbólica como biológicamente, con la fecundidad de una naturaleza generosa. Por lo mismo De Rokha se pregunta, en medio de una agonía de quien ama los frutos cálidos, “Es tan lenta la agonía de aquel que ama los frutos cálidos / ¿Quién en la hora de la muerte no adorará la alegría de los juncos? / ¿Quién no abocará la aventura de las ondas que nunca se detienen?" (Arteche, 1984: 160). La nostalgia es evidente, misma que está presente en el poema de Jorge Teillier "En la secreta casa de la noche": una mujer se pasea por su cuarto "como la sombra desnuda de los manzanos en el muro" (Arteche, 1984: 231). Mujer pecado/desnudez simbólica/manzana prohibida son tópicos más que sugerentes para entender que la culpa de la pudrición y de la muerte no es de las frutas, sino de los hombres, porque luego del crimen en el Paraíso, los culpables se enfermaron de la fruta mal habida de acuerdo a Armando Uribe en "Cuentan los hombres" y por ello, y solo después de ello, los gusanos de la manzana se apoderaron de la tierra (Arteche, 1984: 223). Una verdadera "muerte en la tierra", tal como plantea Gabriela Mistral en "La nuez vana", en donde se entrega una nuez a un hombre advirtiéndole el tiempo de espera para poder ser consumida, en primavera: 
Pero él la partió
sin más espera
y vio caer el polvo
de la nuez huera;
se llenó la mano
de muerte negra,
y la lloró y lloró
la noche entera... (Mistral, 2010: 149-150)

Luego de esto, hay que apresurarse en sepultarla, para que Dios no la vea "y toque con sus manos la muerte en la tierra". Hay aquí una especie de alegoría del apresuramiento, de la cosecha del fruto antes de tiempo: en vez de disfrutarlo, aparece la muerte. No parece una muerte asociada directamente con la semilla, sino que es un problema del hombre alejado de la tierra, de los ciclos de la naturaleza, del campo lindo. La nostalgia se mantiene y se establece a través de los errores del hombre desvinculado de lo natural. Estas ideas quedan claras siguiendo a la misma autora en otros poemas frutales, de tono alegre y juguetón, "Gateando sigues las frutas, / como niñas que se desbandan,/y son los nísperos fundidos/y las dunas piñas tatuadas..." (Mistral, 2010: 150), e incluso con especies de consejo de manipulación de la fruta, como en el poema "La fresa": "No magulles a la tierra,/no aprietes a la olorosa/Por el amor de ella abájate,/ huélela y dale la boca" (Mistral, 2010: 167).

$Y$ es que la fruta ha trascendido en el imaginario popular como algo que da vida, no muerte; que sana, no que enferma, lo cual puede rastrearse en el Folclor Médico de Oreste Plath, en donde aparecen diversas frutas (manzana, naranja, sandía, uva, limones, membrillos, higos e higuera) en sus aspectos curativos no científicos. Tanto es así, que dichas cualidades se traspasaron al cancionero popular infantil, como es el caso del "Burro Enfermo": para el corazón, el doctor receta jarabe de limón y, cuando ya no le duele nada, es porque el médico le ha dado jarabe de manzana. 


\section{Conclusión}

Termina aquí un recorrido que comenzó en el siglo VIII, en Europa y Medio Oriente, pasando por los siglos XIV y XVII europeos y culminando en el XX, en Chile. Durante todo el recorrido, hemos podido apreciar el papel que la fruta y los frutales han jugado en la historia a través del análisis de obras literarias de importancia universal. La construcción, lenta, con avances y retrocesos, de una cultura de apreciación de la fruta, ha sido posible de seguir gracias a este análisis. Y Chile no quedó inmune a este influjo. El movimiento iniciado en Medio Oriente, trasladado a Europa y luego a América vía España, sembró en este país el amor por el árbol frutal, por el campo florido y fértil., y la fruta representó en distintos períodos su presencia evocadora de cosas exquisitas, un paisaje, un aroma, una mujer, un amor. Evidentemente, sus usos simbólicos se fundieron con las tradiciones propias de las culturas originarias, cuyas expresiones literarias en nuestro país solo comienzan a ocupar una presencia más fuerte recién en las últimas décadas del siglo $X X$, lo que abre otro campo para continuar estudiando esta relación. Pero luego de la mitad del siglo también se harán presentes los riesgos que se ciernen sobre esta visión mágica del mundo. La modernización agrícola, mediante la presencia de empresas extranjeras, será denunciada por Pablo Neruda en su Canto general (1981), como la amenaza a esta frágil Arcadia:

Cuando sonó la trompeta, estuvo

todo preparado en la tierra,

y Jehová repartió el mundo

a Coca-Cola Inc., Anaconda,

Ford Motors, y otras entidades:

la Compañía Frutera Inc.

se reservó lo más jugoso,

la costa central de mi tierra,

la dulce cintura de América. 


\section{Bibliografía}

Abduco, Ricardo. "La reciprocidad y el don no son la misma cosa". Cuadernos de Antropología Social 26 (Buenos Aires 2007). 107-124.

Acevedo Hernández, Antonio. Canciones populares chilenas. Santiago: Ercilla, 1939.

Amar, M. La construcción social de la sexualidad en Chile (1973-2005). Tesis para optar al título de Sociológo. Universidad de Chile, 2005. <http://www.tesis.uchile.cl/tesis/ uchile / 2005 / amar_m / sources / amar_m.pdf $>$. Consultado el 17 de julio de 2013.

Arteche Miguel et. al. Poesía chilena contemporánea. 2da. Edición. Santiago: Andrés Bello, 1984.

Berque, A. El pensamiento paisajero. Madrid: Biblioteca Nueva, 2009.

Bidegain, Ana María. "Sexualidad, Sociedad, Estado y Religión: los controles de la sociedad y la imposición del matrimonio monogámico en el mundo colonial hispano americano". Revista de Estudos da Religião 3 (Brasil 2005). 40-62.

Castro, Amalia. "La higuera, el alcohol y el diablo en los relatos campesinos de la zona centro sur de Chile". Estudios Avanzados 16 (Santiago de Chile 2011). 139-159.

Castro, Amalia. "La higuera y la noche de San Juan: una perspectiva simbólica". Perspectivas jóvenes sobre la historia de Chile. Santiago de Chile, Ediciones Universidad Finis Terrae, 2012. 51-66.

Castro, Amalia; Castillo, Valentina; Hernández, Julio; Licanqueo, Felipe; Molina, Eduardo; Reyes, Nélida; Rojas, Benjamín; Ubilla, Mauricio; Yáñez, Milton. "Fruta y fiesta. Presencia de la fruta en la vida campesina: el regalo precioso", en Lacoste, Pablo y Yuri, José Antonio (comp.) Frutales, cultura y sociedad. Un recorrido histórico de la fruticultura chilena hasta nuestros días. Santiago de Chile, 2013: II parte, capítulo 16. Inédito. 
Claro Valdés, Samuel. Chilena o cueca tradicional, de acuerdo con las enseñanzas de Don Fernando González Marabolí. Santiago: Universidad Católica de Chile, 1994.

Coz Lanz, Aguedita. "Revisión Histórica del paisajismo de la Ciudad Universitaria de Caracas, patrimonio común universal". Apuntes 2, Vol. 22 (Bogotá 2009). 156-171.

Curtius, Ernst Robert. Literatura europea y edad media Latina (I). España, Fondo de cultura Económica, 1999.

De Rokha, Pablo. Epopeya de las comidas y bebidas en Chile. Santiago, Editorial Universitaria, 1949.

Felsenhardt, Cristina. "Aprendiendo de los paisajes regionales". Arq 71 (Santiago, abril 2009). 76-79.

Gana, Federico. Días de Campo. Santiago, Imprenta Universitaria, 1916.

Lacoste, Pablo y Castro, Amalia. “Apreciación de la fruta en obras literarias (II) entre comedias picarescas y celebraciones del poder (siglos XIV-XVII)". Literatura y Lingüística 27 (Santiago de Chile, mayo 2013). 15-32.

Lacoste, Pablo; Castro, Amalia y Yuri, José Antonio. “Construcción de la cultura de apreciación de la fruta: aporte de Las Mil y Una Noches". Varia Historia 48 (Minas Gerais, julho-dezembro de 2012).

Mauss, Marcel. “Ensayo sobre el don (Sobre los dones y la obligación de hacer regalos)". Année Sociologique, segunda serie. Madrid, 1924.

Melón Jiménez, Miguel Ángel. “La reinvención de una Arcadia perdida. Quimeras y realidades de la sociedad rural castellana en el ocaso del Antiguo Régimen”. En Pérez Álvarez, María José y Martín García, Alfredo (eds.) Campo y campesinos en la España moderna. Culturas políticas en el mundo hispano. León, Fundación Española de Historia Moderna, 2012. 181-206.

Miaja de la Peña, María Teresa. "El placer por la comida y la bebida. El libro del buen amor como tratado gastronómico". UNAM， 2009. <http://www.letras.ufmg.br/ 
espanhol / Anais / anais_paginas_\%2015022009/

El\%20placer\%20por.pdf>. Consultado el 17 de julio de 2013.

Mistral, Gabriela. En verso y prosa. Antología. Lima: Alfaguara, 2010.

Moncrieff, Henry. "Sexualidad y sociedad moderna: el saber que aún no somos del todo libres". A parte Rei (revista de Filosofía) 50 (España 2007). 1-12.

Molina Núñez, Julio y Araya, Juan Agustín. Selva Lírica. Estudios sobre los poetas chilenos. Santiago: Imprenta Universo, 1917.

Molina Palma, Ángel Miguel. "Simbología de la fiesta de la Naranja" $<$ http: / / www.adurcal.com/enlaces / molina / FIESTAdeLaNaranja/SIMBOLOGIA_FIESTA_ NARANJA/SIMBOLOGIA_FIESTA_NARANJA. htm. 2004>. Consultado el 19 de julio de 2013.

Navarrete, Micaela (Compilación y estudio). Aunque no soy literata. Rosa Araneda en la poesía popular del siglo XX. Santiago: Dirección de Bibliotecas, Archivos y Museos, 1998.

Navarrete, Micaela y Daniel Palma (Compilación y estudio). Los diablos son los mortales. La obra del poeta popular Daniel Meneses. Santiago: Dirección de Bibliotecas, Archivos y Museos, 2008.

Neruda, Pablo. Canto general. Caracas: Biblioteca Ayacucho, 1981.

Nogué, Joan y De San Eugenio Vela, Jordi. "La dimensión comunicativa del paisaje: Una propuesta teórica y aplicada". Revista de Geografía Norte Grande 49 (Santiago, 2011). 25-43.

Pavez, Héctor (Intérprete). El folklore de Chile. Vol. XX. Santiago: EMI, 1970.

Pérez Rioja, J. Diccionario de Símbolos y Mitos. Madrid: Editorial Tecnos, 1969.

Reixach Coll, Magda; Cervera Ral, Pilar; Salas-Salvadó, Jordi. "La alimentación en la cultura egipcia". En Jordi Salas Salvadó, Pilar García-Lorda y José Ma. Sánchez 
Repollés (eds.) La alimentación y la nutrición a través de la historia. Barcelona, Glosa, 2005. 35-61.

Rubio Peñas, María Guadalupe. "Los bodegones velazqueños”. Revista de Claseshistoria. Publicación digital de Historia y Ciencias Sociales, Art. No 254, 2011. <http://www. claseshistoria.com/revista/2011/ articulos / rubiobodegones-velazquez.pdf $>$. Consultado el 17 de julio de 2013.

Sánchez Montañés, Emma. El potlach. Una institución nativa actual entre los pueblos nativos de la costa noroeste. Madrid: Universidad Complutense de Madrid, 2009.

Salinas, Maximiliano. Canto a lo divino y religión popular en Chile hacia 1900. Madrid: Ediciones Rehue, 1985.

Varas, José Miguel y González, Juan Pablo. En busca de la música chilena. Crónica y antología de una historia sonora. Santiago: Publicaciones del Bicentenario, 2005.

Vera Gamboa, Ligia. "Historia de la sexualidad". Revista Biomédica 2, Vol. 9 (México 1998). 116-121. 
